\title{
ECONOMICS
}

\section{ACCOUNTING FOR HETEROGENEITY IN THE MEASUREMENT OF HOSPITAL PERFORMANCE}

by

Philippe K Widmer

and

Peter Zweifel

Socioeconomic Institute

University of Zurich

Switzerland

and

Mehdi Farsi

Department of Management

Technology and Economics

ETH Zurich

Switzerland

DISCUSSION PAPER 10.21 


\title{
Accounting for Heterogeneity in the Measurement of Hospital Performance
}

\author{
Philippe K. Widmer ${ }^{*, a}$, Peter Zweifel ${ }^{\mathrm{a}}$, Mehdi Farsi ${ }^{\mathrm{b}}$ \\ ${ }^{a}$ Socioeconomic Institute, University of Zurich, Switzerland \\ ${ }^{b}$ Department of Management, Technology and Economics, ETH Zürich, Switzerland
}

\begin{abstract}
With prospective payment of hospitals becoming more common, measuring their performance is gaining in importance. However, the standard cost frontier model yields biased efficiency scores because it ignores technological heterogeneity between hospitals. In this paper, efficiency scores are derived from a random intercept and an extended random parameter frontier model, designed to overcome the problem of unobserved heterogeneity in stochastic frontier analysis. Using a sample of 100 Swiss hospitals covering the years 2004 to 2007 and applying Bayesian inference, significant heterogeneity is found, suggesting rejection of the standard cost frontier model. Estimated inefficiency decreases even below the 14 percent reported by Hollingsworth (2008) for European countries. Accounting for unobserved heterogeneity would make hospitals rated below 85 percent efficiency according to the standard model gain up to 12 percentage points, serving to highlight the importance of heterogeneity correction in the estimation of hospital performance.
\end{abstract}

Key words: Hospital efficiency, unobserved heterogeneity, Bayesian inference, Switzerland, Stochastic Frontier Analysis

$J E L: \mathrm{C} 11, \mathrm{C} 33, \mathrm{D} 24, \mathrm{I} 18$

* Corresponding author: Philippe Widmer, Socioeconomic Institute, University of Zurich, Hottingerstrasse 10, CH-8032 Zurich, Switzerland. Phone: +41 (0)44 63422 70, Fax: +41 4463449 87, E-mail: philippe.widmer@soi.uzh.ch 


\section{INTRODUCTION}

Performance-based prospective hospital payment has recently been introduced in several countries. It has greatly increased the importance of accurately measuring firm-specific performance, defined here in terms of operating costs per casemix-adjusted patient case. The challenge for policy makers is to pay for efficiency; however, this calls for filtering out differences that are caused by inefficiencies rather than heterogeneities due to exogenous influences.

In response to this need, there has been a growing body of research into the determinants of cost variability between hospitals (see Hollingsworth, 2008, Jacobs et al., 2006, and Worthington, 2004 for overviews of the literature). Specifically, the meta-analysis by Hollingsworth (2008) finds evidence of inefficiency in the hospitals of the United States and several European countries, amounting to a potential for cost reduction of 18 percent and 14 percent, respectively. Compared to these estimates, Switzerland is on the high side with Steinmann and Zweifel (2003), based on a Data Envelopment Analysis (DEA), coming up with 30 percent. In a comparison with Germany (the land of Saxony), Steinmann et al. (2004) once more found Swiss hospitals to be relatively inefficient. Using a Stochastic Frontier Analysis (SFA), Farsi and Filippini (2006) put the potential of cost reduction to 20 percent on average, which would translate into 7 percent of Switzerland's total health care expenditure (55 bn CHF) in 2007. However, these estimates do not account for heterogeneity in production technology, which is likely to be particularly marked due to Swiss federalism. Indeed, each of the 26 cantons allocates capital to its public hospitals according to its own criteria and often on a case-by-case basis. This results in differences in technology that are largely exogenous to Swiss hospitals. Controlling for them may therefore lead to inefficiency estimates more in line with those cited.

Following the pioneering contribution by Farrell (1957), cost efficiency is defined as the ratio of observed cost to a value on the estimated cost frontier ${ }^{1}$. In the case of SFA introduced by Meeusen and van den Broeck (1977) and Aigner et al. (1977), this ratio is given by

$$
\frac{C_{i}}{C_{S}\left(X_{i} ; \alpha, \beta\right)}=e^{u_{i}+y_{i}}
$$

with $C_{i}$ is (arithmetic) the cost of hospital $i=1, \ldots, N, C_{S}\left(X_{i} ; \alpha, \beta\right)$ is an estimated minimum cost for outputs and input prices comprised in a $N \times(K+1)$ matrix $X, \alpha$ is the unknown intercept, $\beta$ is a $K \times 1$ vector of unknown slope parameters of the cost function, $u_{i}$ is a random term with positive values only reflecting inefficiency, and $v_{i}$ a conventional random error (see Section 2 below for details). The

Simple cost ratios, often used for policy purposes, are not sufficient because they neglect both economies of scale and heterogeneity of technology. 
major advantage of SFA over DEA is that it can distinguish between inefficiency $u_{i}$ and unexplained heterogeneity $v_{i}$ in cost variability. However, a remaining criticism has been that SFA as well as DEA assume an identical production technology for all hospitals whereas particularly in federalist countries such as Switzerland, hospitals operate in different regulatory environments, causing them to provide health care services using different technologies. In the Standard Frontier Model (SFM), this unobserved heterogeneity can bias the estimates of the inefficiency scores $u_{i}$ (see also Greene, 2004a).

There have been several approaches for dealing with this problem. The first is to introduce fixed effects in the SFM or in the distribution of $u_{i}$ (see. e.g. Worthington, 2004). Since the choice of the dummy variables must rely on observable characteristics of the hospital, this solution is limited to 'observable' heterogeneity, leaving potential for 'unobservable' heterogeneity to bias estimated inefficiency scores. Provided panel data available, a true random effects model can be estimated (see e.g. Farsi and Filippini, 2008; Farsi et al., 2006; Greene, 2005b; Greene,-2004b). This is a special case of the Random Intercept Frontier Model (RIFM) to be presented below, which enables cost frontiers to vary between hospitals. Still, the RIFM is not without limitations because it only allows the intercept $\alpha$ to be stochastic and assumes heterogeneity to be homoscedastic. Additional flexibility is afforded by the Random Parameter Frontier Model (RPFM), a generalization of the SFM and the RIFM, which additionally allows the slopes $\beta$ vary between hospitals. Implementation of RPFM until recently was hampered by the requirement of large computational power and panel data of sufficient quality. Improvement on both counts have rendered them feasible in the meantime (see e.g. Widmer, 2010; Huang, 2004; Orea and Kumbhakar, 2004; Tsionas, 2002).

In this paper, we analyze the influence of unobserved heterogeneity between Swiss hospitals using a SFM, a RIFM, and an extended RPFM for SFA. Section 2 contains additional details for these models as well as for the Bayesian approach adopted in the model specification and parameter estimation. The database of about 100 Swiss hospitals covering the years 2004 to 2007 is presented in Section 3. Estimation results confirm the existence of unobserved heterogeneity in Swiss hospitals, suggesting rejection of the SFM. On average, the SFM overestimates Swiss hospital inefficiency by about 6 percent. Section 4 considers the implications of this study for hospital managers and policy makers, and concludes.

\section{MODELING UNOBSERVABLE HETEROGENEITY}

It is common practice to define heterogeneity as time-invariant cost variation that is exogenous in the sense that it cannot be manipulated by management at least in the short run. This definition is 
adopted here ${ }^{2}$. As a benchmark, the specification of the cost function in the presence of observable heterogeneity is presented first (Section 2.1); this provides the point of departure for the modeling of unobservable heterogeneity in Section 2.2, which likely is the more important component given that the quality of (largely non-profit) hospital management is not easily measured.

\subsection{The Standard Frontier Model with Observable Heterogeneity}

When heterogeneity is perfectly observable, the SFM can be augmented in a way permitting to estimate consistent efficiency scores (Pitt and Lee, 1981). Let there be repeated observations $t=$ $1, \ldots, T$ for all hospitals $i=1, \ldots, N$, and let heterogeneity $Z_{i}$ be completely reflected by a $N \times L$ matrix of observable, time-invariant covariates. Using a Cobb-Douglas cost function in logs for simplicity, the cost frontier can be specified as,

$$
\begin{aligned}
C_{i t} & =\alpha+\gamma^{\prime} Z_{i}+\beta^{\prime} X_{i t}+\gamma^{\prime} X_{i t} Z_{i}+u_{i}+v_{i t}, \quad i=1, \ldots, N, t=1, \ldots, T, \\
u_{i} & \stackrel{i i d}{\sim} f_{N}^{+}\left[0, \sigma_{u}^{2}\right] \text { with } \operatorname{Cov}\left(u_{i} ; \alpha, X_{i t}, Z_{i}, v_{i t}\right)=0, \\
v_{i t} & \stackrel{i i d}{\sim} f_{N}\left[0, \sigma_{v}^{2}\right] \text { with } \operatorname{Cov}\left(v_{i} ; \alpha, X_{i t}, Z_{i}, u_{i}\right)=0,
\end{aligned}
$$

with parameters defined in the Introduction section. Note that observable heterogeneity enters the cost function in two ways. First, the intercept $\alpha$ is augmented by a hospital-specific term $\gamma^{\prime} Z_{i}$. This is called separable heterogeneity because it captures cost variability that is unrelated to the hospital's technology, such as size of its catchment area ${ }^{3}$. Second, the slopes $\beta$ pertaining to outputs and factor prices are individualized by $\gamma^{\prime} X_{i t} Z_{i}$. This is non-separable heterogeneity reflecting differences in technology such as the amount and vintage of capital in use.

In this model, firm-specific inefficiency $u_{i}$ is assumed to be time-invariant, uncorrelated with the deterministic part of the cost function as well as with random noise $v_{i t}$, and to follow a one-sided distribution supported on the interval $[0, \infty)$ such as the half normal, truncated normal, exponential, gamma or Weibull distribution. Time variation can be achieved with a systematic time trend as in Battese and Coelli (1992)

$$
u_{i t}=u_{i} \cdot e^{\eta(t-T)} .
$$

\footnotetext{
2 On the longer run, the choice of technology can be influenced by hospital management. The presence of inferior technology becomes a component of management inefficiency in this case.

3 Greene (2005a) permits correlation between separable heterogeneity and production technology in his true fixed effects model.
} 
Alternatively one could model inefficiency as a time-invariant fixed effect (Schmidt and Sickles, 1984), which allows for correlation with production technology $y^{4}$ But because heterogeneity is assumed to be time-invariant here, this variant will not be pursued.

Given Eqs. 2 to 4 (with Eq. 5 as an option), cost variability in logarithms is given by

$$
C_{i t}-C_{H}\left(X_{i t}, Z_{i} ; \alpha, \beta, \gamma\right)=u_{i}+v_{i t}
$$

where $C_{H}\left(X_{i t}, Z_{i} ; \alpha, \beta, \gamma\right)$ is individualized for each hospital as shown in Eq. 2. It enables the hospital regulator to separate cost variability related to differences in technology from inefficiency $u_{i}$ and random noise $v_{i t}$. The resulting inefficiency scores are no longer biased by heterogeneity and can be used for performance-based reimbursement.

However, this result does not hold as soon as heterogeneity is not completely observable but has an unobservable component $Z_{i}^{*}$, resulting in additional terms $\gamma^{\prime} Z_{i}^{*}$ and $\gamma^{\prime} X_{i t} Z_{i}^{*}$ in Eq. 2 . If the regulator uses the conventional benchmark $C_{s}$ of Eq. 1, the residuals become

$$
C_{i t}-C_{S}\left(X_{i t} ; \alpha, \beta\right)=\gamma^{\prime} Z_{i}^{*}+\gamma^{\prime} X_{i t} Z_{i}^{*}+u_{i}+v_{i t}
$$

The existence of (time-invariant) unobservable heterogeneity $Z_{i}^{*}$ now causes bias in the measurement of hospital performance in two ways:

- Rather than estimating true inefficiency $u_{i}$, Eq. 2 will estimate an artificially augmented inefficiency term $\widetilde{u_{i t}}=u_{i}+\gamma^{\prime} Z_{i}^{*}+\gamma^{\prime} X_{i t} Z_{i}^{*}$

- To the extent that unobserved heterogeneity $Z_{i}^{*}$ is correlated with either observed heterogeneity $Z_{i}$ or outputs and factor prices $X_{i t}$ estimates of technology parameters $\alpha$ and $\beta$ are biased as well since $\operatorname{Cov}\left(\widetilde{u_{i t}}, Z_{i}\right) \neq 0, \operatorname{Cov}\left(\widetilde{u_{i t}}, X_{i t}\right) \neq 0$.

With both inefficiency scores and technology parameters biased, prospective payment runs the risk of rewarding some hospitals for being seemingly efficient while punishing others for being seemingly inefficient.

U.S. experience with prospective payment suggests that unobservable heterogeneity could be substantial. If performance-based reimbursement took into account all relevant determinants of hospital cost, one would expect hospitals to discard technologies giving rise to characteristics that are not paid

\footnotetext{
$4 \quad$ The fixed effect model has at least two drawbacks: (1) it only measures relative inefficiency, (2) no time-invariant
} technology parameters are allowed in the cost function. 
for and to move to the cost-efficient level. However, Keeler (1990) found that U.S. hospitals still have a great deal of unexplained cost variability although prospective payment had been in place since 1983. One reason is that changes in hospital technology are particularly costly, causing hospitals to be slow in adopting new technologies. Evidently, more advanced estimation techniques are necessary to disentangle latent heterogeneity from inefficiency for prospective hospital payment to have the desired efficiency-enhancing effects ${ }^{5}$.

\subsection{The Random Parameter Model with Observable and Unobservable Heterogeneity}

The discussion of the preceding subsection led to the conclusion that in the case of hospitals, part of their technological heterogeneity is unobservable for years to come. Therefore, reimbursement arguably should take into account both observable and unobservable heterogeneity. One way to achieve this is the RPFM (the RIFM allows only the intercept rather than all parameters to be random and will not be expounded separately below). A RPFM estimates an individual cost function for each hospital, admitting of both observable and unobservable heterogeneity (see e.g. Widmer, 2010; Greene, 2004b; Huang, 2004; Orea and Kumbhakar, 2004; Tsionas, 2002). To save on notation, the case of unobservable heterogeneity only is presented below. No ex-ante information on heterogeneity is needed, except for the assumption that it is time-invariant and normally distributed over individual hospitals. This is achieved by introducing a time-invariant random variable $w_{i}$ that changes the intercept of the cost function to become $\alpha_{i}=\alpha+w_{i}$ (separable heterogeneity) and to the slope parameters to become $\beta_{i}=\beta+w_{i}$ (non-separable heterogeneity), resulting in

$$
\begin{aligned}
& C_{i t}=\left(\alpha+w_{i}\right)+\left(\beta+w_{i}\right)^{\prime} X_{i t}+u_{i t}+v_{i t}, \text { or } \\
& C_{i t}=\alpha_{i}+\beta_{i}^{\prime} X_{i t}+u_{i t}+v_{i t},
\end{aligned}
$$

In the special case where $w_{i}$ captures all existing heterogeneity, the RPFM can be transformed back into a SFM by substituting $w_{i}$ by $\gamma^{\prime} Z_{i}$ in Eq. 8 .

However, this specification is somewhat restrictive because it assumes both the intercept and the slopes of the cost function to be time-independent. This neglects the fact that new medical technology affects the whole hospital industry in very much the same way (such as the introduction of SCAT scanners). Denoting these changes by a vector of time dummies $M_{t}$, Eq. 9 can be generalized to read,

$5 \quad$ As stated by Newhouse (1996), one option to overcome this problem is to use non fully prospective reimbursement systems, that are not fully prospective. 


$$
\begin{aligned}
& C_{i t}=\alpha_{i t}+\beta_{i t}^{\prime} X_{i t}+u_{i t}+v_{i t} \text { with } \\
& \alpha_{i t}=\overline{\bar{\alpha}}+\gamma^{\prime} Z_{i}+\delta^{\prime} M_{t}+w_{i} \text { and } \overline{\alpha_{i t}}=\overline{\bar{\alpha}}+\gamma^{\prime} Z_{i}+\delta^{\prime} M_{t} \\
& \beta_{i t}=\overline{\bar{\beta}}+\gamma^{\prime} Z_{i}+\delta^{\prime} M_{t}+w_{i} \text { and } \overline{\beta_{i t}}=\overline{\bar{\beta}}+\gamma^{\prime} Z_{i}+\delta^{\prime} M_{t}
\end{aligned}
$$

This specification allows to disentangle inefficiency from unobservable heterogeneity both variable and time-invariant. Separable heterogeneity is captured by the random intercept $\alpha_{i t}=\overline{\bar{\alpha}}+\gamma^{\prime} Z_{i}+$ $\delta^{\prime} M_{t}+w_{i}$, where $\overline{\bar{\alpha}}$ is the mean intercept over all hospitals. Non-separable heterogeneity in technology parameters is captured by a $(K \times 1)$ vector of hospital-specific parameters $\beta_{i t}=\overline{\bar{\beta}}+\gamma^{\prime} Z_{i}+\delta^{\prime} M_{t}+w_{i}$.

To derive individual effects, assume $\alpha_{i t}$ and $\beta_{i t}$ to follow a multivariate normal distribution

$$
\left(\begin{array}{c}
\alpha_{i t} \\
\beta_{i t}
\end{array}\right) \sim f_{M N}\left[\left(\begin{array}{c}
\overline{\alpha_{i t}} \\
\overline{\beta_{i t}}
\end{array}\right), \Sigma\right], \quad \text { with } \Sigma \sim f_{W}\left[\begin{array}{ll}
\sigma_{\alpha_{i t}}^{2} & \sigma_{\alpha_{i t}, \beta_{i t}} \\
\sigma_{\alpha_{i t}, \beta_{i t}} & \sigma_{\beta_{i t}}^{2}
\end{array}\right] \text {, }
$$

where $\overline{\alpha_{i t}}=\overline{\bar{\alpha}}+\gamma^{\prime} Z_{i}+\delta M_{1}$ and $\overline{\beta_{i t}}=\overline{\bar{\beta}}+\gamma^{\prime} Z_{i}+\delta M_{t}$ are the expected group-specific mean effects for given observable heterogeneity and a given time period. Variance $\Sigma$ is Wishart distributed with a $((K+1) \times(K+1))$ positive definite covariance matrix $S=\left(\sigma_{\alpha_{i t}}^{2}, \sigma_{\beta_{i t}}^{2}, \sigma_{\alpha_{i t}, \beta_{i t}}\right)$, denoting unobserved heterogeneity between hospitals. For $\Sigma=0$ no heterogeneity exists and the random parameter model simplifies to a SFM with no variation in $\beta_{i t}$ and $\alpha_{i t}$. Thus, there is no risk of wrongly identifying inefficiency as technological heterogeneity in a systematic way.

For the Bayesian estimation to be performed in Section 3, the posterior distribution for the random parameter model needs to be derived. It is given by

$$
\begin{aligned}
p(\alpha, \bar{\alpha}, \overline{\bar{\alpha}}, \beta, \bar{\beta}, \overline{\bar{\beta}}, \gamma, & \left.\delta, u, \Sigma, \sigma_{v}^{-2}, \sigma_{u}^{-2} ; C, X, Z, M\right) \propto p\left(\overline{\bar{\alpha}}, \overline{\bar{\beta}}, \gamma, \delta, \Sigma, \sigma_{v}^{-2}, \sigma_{u t}^{-2}\right) \\
& \times \prod_{i=1}^{N} \prod_{t=1}^{T} \frac{1}{\sqrt{2 \pi \sigma_{v}^{2}}} \exp \left[-\frac{1}{2 \sigma_{v}^{2}}\left(C_{i t}-\left[\alpha_{i t}+\beta_{i t}^{\prime} X_{i t}+u_{i t}\right]\right)\right] \\
& \times \prod_{i=1}^{N} \prod_{i=1}^{T}(2 \pi)^{-K / 2}|\Sigma|^{-1 / 2} \exp \left[-\frac{1}{2}\left(\left(\begin{array}{c}
\alpha_{i t} \\
\beta_{i t}
\end{array}\right)-\left(\begin{array}{c}
\bar{\alpha}_{i t} \\
\bar{\beta}_{i t}
\end{array}\right)\right)^{\prime} \Sigma^{-1}\left(\left(\begin{array}{c}
\alpha_{i t} \\
\beta_{i t}
\end{array}\right)-\left(\begin{array}{c}
\left.\overline{\alpha_{i t}}\right) \\
\overline{\beta_{i t}}
\end{array}\right)\right]\right. \\
& \times \prod_{i=1}^{N} \prod_{t=1}^{T} p\left(u_{i t}, \sigma_{u}^{-2}\right)
\end{aligned}
$$

where probability distributions $p\left(\overline{\bar{\beta}}, \gamma, \delta, \Sigma, \sigma_{v}^{-2}, \sigma_{u}^{-2}\right)$ for the priors remain to be specified in Section 3.1. The likelihood function in Eq. 12 is as in Griffin and Steel (2007), normally distributed with $\sigma_{v}^{2}$ as the variance of the random noise $v_{i t}=C_{i t}-\left[\alpha_{i t}+\beta_{i t}^{\prime} X_{i t}+u_{i t}\right]$. The last term of Eq. 12 points to a gain 
in flexibility over classical maximum likelihood applications, where a joint density function of the random noise $v$ and the inefficiency term $u$ is specified. Here, only random noise enters the likelihood function, while inefficiency is estimated as a latent variable along with the other parameters of the cost function.

The random intercept $\alpha_{i t}$ and technology parameters $\beta_{i t}$ are estimated at three levels. At the first level, the overall influences on hospital costs $(\overline{\bar{\alpha}}, \overline{\bar{\beta}})$ are determined, corresponding to the first factor following the proportionality sign of Eq. 12; the second-level estimates of group-specific effects $\left(\overline{\alpha_{i t}}\right.$, $\left.\overline{\beta_{i t}}\right)$ defined in Eq. 10 and the third-level estimates of individual values $\left(\alpha_{i t}, \beta_{i t}\right)$ are derived from the multivariate normal distribution shown in Eq. 12. Finally, inefficiency $p\left(u, \sigma_{u}^{-2}\right)$ given by the last factor of Eq. 12 is estimated at two levels. The first-level estimate corresponds to the population mean. The second-level estimates yield firm-specific inefficiency scores $u_{i t}$.

Note that estimates of the unknown parameters can be derived by the marginal posteriors of Eq. 12. However, it is not always possible to compute the posteriors analytically. Therefore, iterative Monte Carlo Markov Chain (MCMC) simulation is used, which involves iterative sampling from posterior parameter densities. Here, we use WINBUGS to derive the estimates (see Ntzoufras, 2009 for an introduction to Bayesian analysis with WINBUGS). The corresponding computational codes are shown in Table 5 in the Appendix.

The model formulation of Eq. 10 is quite general, containing many other variants of RPFM cited as special cases. For example, if $Z_{i}$ and $M_{t}$ turn out to be zero for all covariates, it reduces to the one described by Greene (2004b) where all parameters are allowed to vary between hospitals but are constant over time. Furthermore, if additionally only technology parameters contain heterogeneity, it reduces to the one of Tsionas (2002), with a common intercept for all hospitals. If only the intercept controls for heterogeneity, it corresponds to the true random effects model of Greene (2005a) where all cost functions have the same slopes, adjusting only for separable heterogeneity. This is similar to the applied RIFM but with heterogeneity that is constant over time. Finally, if additionally $w_{i}$ is zero for all parameters, the RPFM reduces to a SFM with no heterogeneity in the cost function.

\section{EMPIRICAL APPLICATION TO SWISS HOSPITALS USING BAYESIAN INFERENCE}

In this section, we analyze the effect of unobserved heterogeneity on the performance of Swiss hospitals with three SFA formulations, a Random Parameter Frontier Model (RPFM) outlined in Section 2.2, a Random Intercept Frontier Model (RIFM) as a special case of the RPFM, and a Standard Frontier Model (SFM) with a time-varying inefficiency term, as in Eq. 5. 


\subsection{Data and Econometric Specification of the Cost Function}

The data used in this study are provided by the annual reports of the Federal Office of Public Health. They include 333 Swiss hospitals for the time period 2004 to 2007, comprising information on 5 university hospitals (K111), 23 central hospitals (K112), 27 large regional hospitals (K121), 46 medium regional hospitals (K122), 46 small regional hospitals (K123), 28 specialized surgery hospitals (K231), and sundry hospitals, viz. psychiatric and rehabilitation clinics. In total, 127 of these 333 units are private, non-subsidized hospitals.

In the interest of comparability, the sundry category was discarded. After purging the data from missing values and outliers, an unbalanced panel of 405 observations of sufficient quality is available. Observations consist of measured variables as follows:

$V C$ : Variable operational expense per year, in thousands of CHF (VC);

$X_{1} \quad$ : CMI-adjusted inpatient cases (PCASES);

$X_{2} \quad$ : Revenue from outpatients (OUTP);

$X_{3} \quad$ : Price of labor, average wage per employee (PL);

$X_{4} \quad$ : No. of beds (BEDS);

$S_{1} \quad$ : No. of internship categories (INTERN);

$S_{2} \quad$ : No. of specialties (SPEC);

$S_{3} \quad$ : Dummy=1 for subsidized public hospitals (SUB);

$S_{4} \quad$ : Share of inpatients with supplementary insurance, in percent (INSUR);

$M_{t}$ : Year dummies for technology improvements, $\mathrm{t}=2005,2006,2007$ (base year=2004)

$Z_{l} \quad$ : Dummy for hospital groups, I=K111, K112, K121, K122, K231 (base group=K123)

Table 1: Descriptive Statistics

\begin{tabular}{|c|c|c|c|c|c|c|c|c|c|c|}
\hline Variable & Mean & Max & Min & Std. Dev. & K111 & $\mathrm{K} 112$ & $\mathrm{~K} 121$ & $\mathrm{~K} 122$ & $\mathrm{~K} 123$ & K231 \\
\hline$V C^{1)}$ & 109,296 & 953,586 & 3,925 & 170,580 & 790,609 & 190,380 & 88,122 & 44,830 & 19,538 & 36,387 \\
\hline PCASES & 7,731 & 52,143 & 497 & 9,679 & 43,046 & 14,651 & 7,093 & 3,796 & 1,545 & 2,741 \\
\hline OUTP & 20,499 & 186,174 & 0 & 33,710 & 142,331 & 42,845 & 14,753 & 6,826 & 2,387 & 6,698 \\
\hline$P L$ & 101 & 188 & 34 & 15 & 106 & 103 & 100 & 100 & 99 & 108 \\
\hline$B E D S$ & 201 & 1,170 & 12 & 213 & 893 & 383 & 207 & 108 & 55 & 69 \\
\hline INTERN & 18 & 134 & 0 & 27 & 118 & 32 & 15 & 10 & 5 & 3 \\
\hline$S P E C$ & 35 & 86 & 4 & 16 & 67 & 50 & 36 & 33 & 24 & 18 \\
\hline$S U B^{2)}$ & 87 & 100 & 0 & 34 & 100 & 100 & 100 & 88 & 80 & 37 \\
\hline$I N S U R^{2)}$ & 25 & 100 & 3 & 20 & 18 & 19 & 20 & 25 & 27 & 47 \\
\hline
\end{tabular}

1) in 1,000 CHF, $1 \mathrm{CHF}=0.8$ USD (2004 exchange rates)

2) in percent, $\mathrm{SUB}=100$ means that 100 percent of all hospitals are subsidized 
Summary statistics are shown in Table 1 for all six hospital groups retained. They suggest that technological heterogeneity between Swiss hospital groups indeed influence cost. University hospitals (K111) for example have the highest variable costs $(V C=790,609)$; this can be attributed to their high values of the two major outputs (PCASES $=43,046$ and $O U T P=142,331)$ and possibly the fact that they are all subsidized ( $S U B=100$ percent) while having a small share of patients with supplementary insurance (INSUR $=18$ percent). However, they also have the most internship programs $(I N T E R N=118)$ and specialties $(S P E C=67)$. Specialized hospitals $(\mathrm{K} 231)$ on the other hand are on average small hospitals with fewer internship programs $(I N T E R N=3)$ and specialties $(S P E C=18)$ but are mostly non-subsidized ( $S U B=37$ percent $)$ while having a high share of supplementary insured patients (INSUR $=47$ percent).

With these data, we can specify a cost function where variable cost $(V C)$ depends on two output categories (PCASES, OUTP), one input price for labor $(P L)$,- one capital stock (BEDS), and four structural variables (INTERN, SPEC, SUB,INSUR). Although some of them could be interpreted as observable indicators of technology (in particular, the number of specialties offered), they are treated as a category of their own here. Intercept and technology parameters are reflected by a linear function of dummies for different hospital groups $(Z)$ and different time periods $(M)$. The underlying short-term Cobb-Douglas cost function (subscripts $i=1, \ldots, N$ and $t=1, \ldots, T$ are dropped for simplicity) therefore reads,

$$
\begin{aligned}
\ln V C & =\beta_{0}+\sum_{m=1}^{4} \beta_{m} \ln X_{m}+\sum_{z=5}^{8} \beta_{z} S_{z}+u+v, \text { with } \\
\beta_{k, k=\{0, m, z]} & =\overline{\bar{\beta}}_{k}+\sum_{l=1}^{6} \gamma_{l, k} Z_{l}+\sum_{\tau=1}^{3} \delta_{\tau, k} M_{\tau}+w .
\end{aligned}
$$

This formulation can be justified on several grounds. First, it is compatible with short-term cost minimization, reflecting the fact that capital (indicated by $B E D S$ ) is predetermined rather than a decision variable. In Switzerland, cantonal hospital planning divisions mainly decide about capacity. Second, the exclusion of user cost of capital from the equation avoids measurement errors since values would have to be imputed, most hospitals not being charged capital user costs. 
In order to conduct Bayesian inference from the posterior given in Section 2.2, prior distributions need to be specified. The values for the hyperparameters are chosen in a way to imply relatively vague but proper priors. In particular, the priors are assumed to be independent,

$$
p\left(\overline{\bar{\alpha}}, \overline{\bar{\beta}}, \gamma, \delta, \Sigma, \sigma_{v}^{-2}, \sigma_{u}^{-2}\right)=p(\overline{\bar{\alpha}}) p(\overline{\bar{\beta}}) p(\gamma) p(\delta) p(\Sigma) p\left(\sigma_{v}^{-2}\right) p\left(\sigma_{u}^{-2}\right)
$$

Here, $p(\overline{\bar{\alpha}})=f_{N}\left[0, \theta_{\overline{\bar{\alpha}}}\right], p(\overline{\bar{\beta}})=f_{N}\left[0, \theta_{\overline{\bar{\beta}}}\right], p(\gamma)=f_{N}\left[0, \theta_{\gamma}\right]$, and $p(\delta)=f_{N}\left[0, \theta_{\delta}\right]$ have a normal distribution with mean zero and a diffuse prior for their corresponding variance $\theta$. The variance of the likelihood function has a gamma distribution $p\left(\sigma_{v}^{-2}\right)=f_{G}\left[\mu, \theta_{\sigma_{v}^{-2}}\right]$ with diffuse shape and scale parameters. Inefficiency is assumed to be half normally distributed $p\left(u, \sigma_{u}^{2}\right)=f_{N}^{+}\left[0, \sigma_{u}^{2}\right]$ with $\sigma_{u}^{2}=$ $f_{G}\left[5,\left(5 * \log (\overline{e f f})^{2}\right)\right]$. This specification is in line with Griffin and Steel (2007) and Koop et al. (1997), permitting to impose a priori information with regard to mean efficiency, $\overline{e f f}=\exp (-\bar{u})$. Following the formulation of Griffin and Steel (2007), $\overline{e f f}=0.875$ is assumed for prior efficiency. Finally, the variance of the random parameters is specified as a Wishart distribution $p(\Sigma)=f_{W}[S]$ in accordance with Eq. 10 with diffuse prior for the covariance matrix $S$.

To obtain posterior estimates, MCMC algorithms were run for 100,000 iterations, with the first 50,000 discarded as a burn-in phase. Different assumptions for priors and starting values converged to roughly the same values, suggesting that convergence to the posterior distribution was achieved.

\subsection{Econometric Results of the Cost Functions and their Cost Variability}

Table 2 presents estimated means and standard errors of the cost function for the Standard Frontier Model (SFM), the Random Intercept Model (RIFM), and the Random Parameter Model (RPFM). The RPFM is presented with estimates for $\overline{\bar{\alpha}}$ and $\overline{\bar{\beta}}$. Results of second level-estimates of the technology parameters and the intercept are shown in Table 5 of the Appendix; they point to a cost-disadvantage of university hospitals (K111) associated with subsidization ( $S U B=100$ percent) that is absent from specialized hospitals (K231). Moreover, the cost function tends to shift up over time, but without affecting the slope parameters. The three variants in Table 2 can be assessed using the DIC information criterion (Spiegelhalter et al., 2002). The lower the DIC-value, the better the goodness of fit of the estimated cost function, indicating that the RPFM has the best model fit, followed by RIFM, with SFM definitely behind. 
Table 2: Econometric Results

\begin{tabular}{|c|c|c|c|c|c|c|}
\hline & \multicolumn{2}{|c|}{ SFM } & \multicolumn{2}{|c|}{ RIFM } & \multicolumn{2}{|c|}{ RPFM } \\
\hline & Estimate & Std. Error & Estimate & Sid. Error & Estimate & Std. Error \\
\hline Constant & 2.176 & $(0.279)$ & 3.334 & $(0.340)$ & 4.948 & (1.109) \\
\hline PCASES & 0.674 & $(0.037)$ & 0.554 & $(0.045)$ & 0.485 & $(0.115)$ \\
\hline OUTP & 0.025 & $(0.004)$ & 0.015 & $(0.004)$ & 0.013 & $(0.011)$ \\
\hline$P L$ & 0.254 & $(0.058)$ & 0.199 & $(0.049)$ & 0.384 & $(0.110)$ \\
\hline$B E D S$ & 0.256 & $(0.039)$ & 0.311 & $(0.044)$ & -0.148 & $(0.127)$ \\
\hline INTERN & 0.004 & $(0.000)$ & 0.001 & $(0.001)$ & 0.008 & $(0.006)$ \\
\hline$S P E C$ & 0.002 & $(0.001)$ & 0.001 & $(0.001)$ & 0.001 & $(0.007)$ \\
\hline$S U B$ & 0.141 & $(0.036)$ & 0.191 & $(0.055)$ & 0.231 & $(0.529)$ \\
\hline INSUR & 0.004 & $(0.001)$ & 0.004 & $(0.001)$ & 0.003 & $(0.007)$ \\
\hline$\sigma_{v}^{2}$ & 0.013 & & 0.003 & & 0.003 & \\
\hline$\sigma_{u t}^{2}$ & 0.025 & & 0.005 & & 0.004 & \\
\hline$\sigma_{\alpha r}^{2}$ & - & & 0.021 & & 0.001 & \\
\hline$\lambda_{u}$ & 0.647 & & 0.180 & & 0.539 & \\
\hline$\lambda_{\alpha}$ & - & & 0.721 & & 0.095 & \\
\hline DIC & -463.470 & & -1100.700 & & -1112.800 & \\
\hline
\end{tabular}

Nevertheless, the three specifications produce fairly minor variations in technology parameters. Estimates also have the expected sign, with the only exception of $B E D$. Being an indicator of capital stock, it should have a negative sign, which only obtains in the RPFM.

However, the main interest of this research revolves about technological heterogeneity that may not be accounted for in the SFM and its influence on estimated inefficiency scores. The relevant estimates are $\sigma_{v}^{2}, \sigma_{u}^{2}$, and $\sigma_{\alpha}^{2}$, which stand for the variance of random noise, inefficiency, and separable heterogeneity, respectively; their relative importance (expressed as a share of total error variance) is given by $\lambda_{u}$ and $\lambda_{\alpha}$. For the SFM, total cost variability is $0.038\left(\sigma_{v}^{2}=0.013, \sigma_{u}^{2}=0.025\right)$, with most variation in the inefficiency term. According to $\lambda_{u}=0.647$, about 65 percent of cost variability is due to inefficiency, a share comparable to the literature cited in the Introduction section. Next, the RIFM with $\sigma_{v}^{2}=0.003, \sigma_{u}^{2}=0.005$, and $\sigma_{\sigma}^{2}=0.021$ confirms the existence of separable heterogeneity. It also indicates a reduction of cost variability by 23 percent (from 0.038 to 0.029 ), due to its ability to capture heterogeneity in the random intercept. Variability due to inefficiency even declines by 80 percent (from 0.025 to 0.005 ) and from 65 percent to 18 percent in relative terms. Most of the cost variability between Swiss hospitals can now be attributed to unobserved separable heterogeneity $\left(\sigma_{\alpha}^{2}=0.021\right)$, accounting for 72 percent of total cost variability. Still, non-separable heterogeneity is likely to exist, biasing coefficients and inefficiency scores.

The RPFM confirms this concern. As to bias, the capital indicator BEDS now has the expected negative sign (although insignificant) while the coefficient of $P L$ attains the high value suggested by the argument that hospital costs are mainly driven by labor cost. As to cost variability, it again 
decreases markedly by 72 percent (from 0.029 RIFM to 0.008 RPFM). Most of the cost variability that cannot be attributed to casemix - equal to 0.042 and estimated by the residual sum of squares of a single regression with $V C$ as a dependent variable and PCASES as the independent variable - can now be explained by the estimated cost function. Interestingly, while $\sigma_{v}^{2}=0.003$ and $\sigma_{u}^{2}=0.004$ change little from RIFM, the variance of separable heterogeneity diminishes drastically from 0.021 to 0.001 , with its relative importance falling from 72 percent to a more plausible 9 percent. Consequently, the relevance of inefficiency increases to 54 percent, comparable to the SFM value.

Table 3: Variance-Covariance Matrix of the Wishart Distribution

\begin{tabular}{lrrrrrrrr}
\hline & PCASES & OUTP & PL & BEDS & INTERN & SPEC & SUB & INSUR \\
\hline PCASES & $0.505^{*}$ & & & & & & & \\
OUTP & -0.338 & $0.372^{*}$ & & & & & & \\
PL & 0.257 & -0.196 & $0.297^{*}$ & & & & & \\
BEDS & -0.216 & 0.171 & -0.132 & $0.257^{*}$ & & & & \\
INTERN & -0.125 & 0.088 & -0.17 & 0.091 & $0.362^{*}$ & & & \\
SPEC & -0.074 & 0.057 & -0.035 & 0.043 & 0.001 & $0.132^{*}$ & & \\
SUB & 0.208 & -0.144 & 0.09 & -0.091 & 0.060 & -0.018 & $0.279^{*}$ & \\
INSUR & 0.389 & -0.318 & 0.267 & -0.238 & -0.159 & -0.081 & 0.159 & $0.584^{*}$ \\
\hline * Significant at the 95\% confidence level.
\end{tabular}

Indeed, the RPFM attributes most of the cost variability to the technology parameters, as can be seen from the covariance matrix of the Wishart distribution in Table 3. The variances on the diagonal show that heterogeneity is strongly related to the output indicator PCASES and the structural variable INSUR, in spite of the fact that PCASES already adjusts for heterogeneity through a casemix index. At least in the Swiss case, this raises doubts about the relevance of the casemix index used to adjust for cost variability in prospective payment. As to the off-diagonal entries, the negative correlation between $B E D S$ and $P L$, although insignificant, points to capital and labor being complements in the hospital sector.

\subsection{Efficiency Scores}

In many countries, public authorities finance major parts of hospital investment and decide about the opening, closing down, and restructuring of hospitals. For these decisions, efficiency scores may provide guidance. However, as shown in Section 3.2, accounting for heterogeneity has an impact on the cost variability attributed to inefficiency $\left(\sigma_{u}^{2}, \lambda_{u}\right)$. Therefore, a comparison of mean efficiency scores, their distribution, and development over time between the three models is of considerable interest. 
Efficient hospitals are on the estimated cost frontier $\left(\widehat{u_{i t}}=0, \widehat{e f f}=1\right)$, those with inefficiency above the frontier $\left(\widehat{u_{i t}}>0, \widehat{e f f}<1\right)$. Since the $u_{i t}$ are in logarithms, one has

$$
\widehat{e f f}_{i t}=\exp \left(-\widehat{u_{i t}}\right)
$$

with $\widehat{u_{i t}}$ simulated from a half normal distribution.

Table 4: Efficiency Values by Model Type and Year

\begin{tabular}{lcccccc}
\hline & Average & Maximum & Minimum & Std. Dev. & Skewness & Kurtosis \\
\hline SFM & 0.89 & 0.96 & 0.73 & 0.04 & -1.07 & 4.23 \\
RIFM & 0.95 & 0.98 & 0.84 & 0.02 & -2.78 & 17.70 \\
RPFM & 0.95 & 0.98 & 0.90 & 0.01 & -2.06 & 12.84 \\
\hline $\mathbf{2 0 0 7}$ & & & & & & \\
SFM & 0.87 & 0.94 & 0.75 & 0.04 & -0.90 & 3.37 \\
RIFM & 0.95 & 0.97 & 0.84 & 0.02 & -3.74 & 20.56 \\
RPFM & 0.95 & 0.97 & 0.90 & 0.01 & -3.09 & 16.53 \\
\hline 2006 & & & & & & \\
SFM & 0.88 & 0.95 & 0.75 & 0.04 & -0.90 & 3.69 \\
RIFM & 0.95 & 0.97 & 0.86 & 0.02 & -2.69 & 15.55 \\
RPFM & 0.96 & 0.97 & 0.94 & 0.01 & -0.54 & 3.57 \\
\hline 2005 & & & & & & \\
SFM & 0.90 & 0.96 & 0.73 & 0.04 & -1.46 & 6.25 \\
RIFM & 0.95 & 0.98 & 0.87 & 0.01 & -1.77 & 11.61 \\
RPFM & 0.95 & 0.98 & 0.91 & 0.01 & -1.35 & 8.60 \\
\hline 2004 & & & & & & \\
SFM & 0.91 & 0.96 & 0.78 & 0.03 & -1.41 & 5.76 \\
RIFM & 0.95 & 0.98 & 0.89 & 0.01 & -0.96 & 5.77 \\
RPFM & 0.95 & 0.97 & 0.92 & 0.01 & -1.13 & 5.42 \\
\hline
\end{tabular}

Starting with the top of Table 4 , the first thing to note is that mean efficiency scores are 0.89 or higher, putting the potential for cost reduction at 11 percent or less. This figure is much closer to the 14 percent reported by Hollingsworth (2008) for other European countries and cited in the Introduction section. However, efficiency scores derived from the SFM are markedly lower than their RIFM and RPFM counterparts. Unobserved heterogeneity therefore does lower estimated efficiency scores, causing the potential for cost reduction to be overstated. Over the observation period, the average SFM score is 0.89 , suggesting a cost reduction potential of 11 percent. Using the RIFM that corrects for separable heterogeneity, one arrives at a mean score of 0.95 , a value comparable to Farsi and Filippini (2008) who estimated a true random effects model. Thus, prospective payment based on a SFM would overestimate the potential for cost reduction by no less than 6 percent, causing financial distress to at least some cost-efficient hospitals who happen to be stuck with inferior technology e.g. due to old buildings. Turning to the RPFM, which distinguishes non-separable from separable 
heterogeneity, one does not find a change away from RIFM mean scores. However, the minimum value is now 0.90 rather than 0.84 , accompanied by a decrease in (negative) skewness and kurtosis.

Figure 1: Efficiency Estimates of the SFM, RIFM, and RPFM for 2004-7

A) Density of the Efficiency Scores

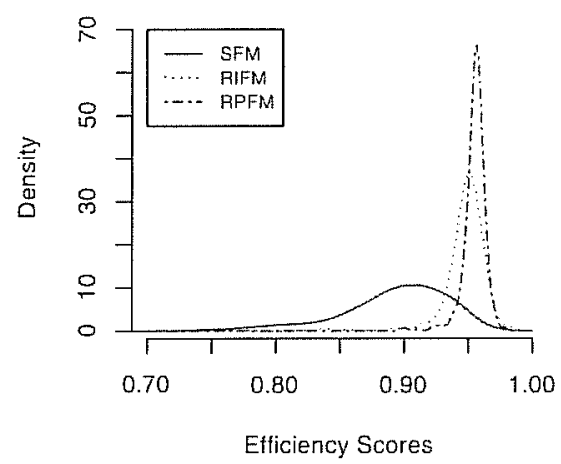

C) SFM vs. RPFM

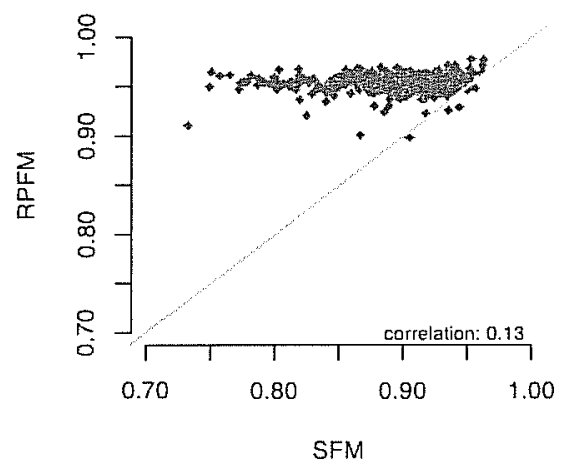

B) SFM vs. RIFM

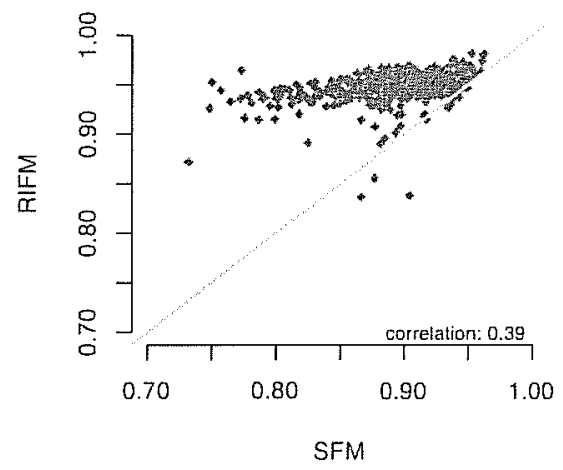

D) RIFM vs. RPFM

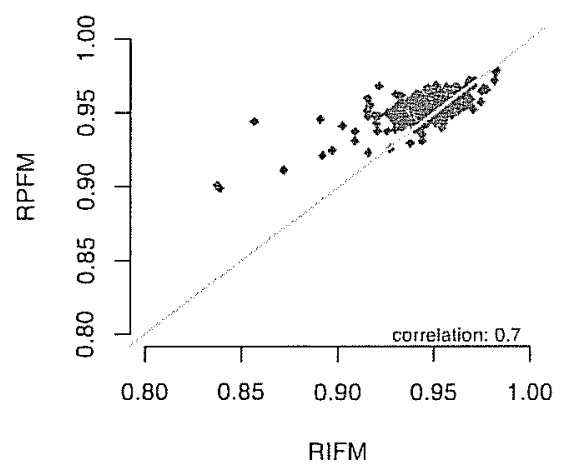

While these differences are evident from panel A of Figure 1, a comparison of individual efficiency scores is even more telling. Panel B of Figure 1 reveals that hospitals that would have been rated below 85 percent efficiency according to SFM gain up to 12 percentage points when the RIFM is applied instead. Panel $\mathrm{C}$ shows that this gain may even reach 15 points when the more general RPFM is used. Finally, the comparison between RIFM and RPFM in panel D of Figure 1 indicates that hospitals with a RIFM score below 0.92 still would benefit from a transition to RPFM, although the gain rarely exceeds 5 percentage points. Therefore, at a given point of time and for a majority of Swiss hospitals, it clearly matters whether or not unobservable heterogeneity is taken into account in performance measurement.

Still, the three models might agree when it comes to development over time. Returning to Table 4, one notices that mean SFM efficiency scores have decreased over time, from 0.91 in 2004 to 0.87 in 2007. In sharp contrast, the RIFM and RPFM measures remained constant. Under the impression of SFM estimates, regulators would therefore have concluded that prospective payments should be cut 
to squeeze increasingly important cost reductions out of the hospital sector. Yet the evidence points to an increased importance of unobservable heterogeneity (see also the hikes in skewness and kurtosis of RIFM and RPFM scores especially in 2007). Such an increase is credible in view of the fact that in response to sluggish economic growth, hospital renovation projects were postponed or downsized. Failure to control for unobservable heterogeneity thus risks to punish more and more harshly those hospitals that are hampered by outdated technology.

\section{CONCLUDING REMARKS}

With prospective reimbursement of hospitals becoming increasingly common, measurement of hospital performance has been gaining in importance. However, measurement can be biased if it fails to account for technological heterogeneity, part of which is unobservable. This paper seeks to shed some light on the importance of both observable and unobservable heterogeneity by estimating a standard cost frontier model, a random intercept cost frontier model, and a random parameter cost frontier model. Bayesian inference is applied to the data of about 100 Swiss hospitals between 2004 and 2007.

Results confirm the existence of unobserved heterogeneity causing some of the cost variability even though inpatient cases are casemix-adjusted. This means that the standard frontier model, which does not control for heterogeneity, is insufficient for deriving unbiased performance measures. In the case of Switzerland, the biases may be substantial. Whereas Hollingsworth (2008) reports a potential for cost reductions of 14 percent for Europe, Farsi et al. (2006) put it to 20 percent for Swiss hospitals covering the years 1997 to 2002. In this paper, a comparable standard frontier model suggests 11 percent for 2004 to 2007, dropping to 5 percent when both observable and unobservable heterogeneity are controlled for. An element-wise comparison reveals that hospitals rated 85 percent efficient and less (using the standard method) would gain up to 12 percentage points. Therefore, quite a few hospitals, although highly efficient in fact, would end up in financial distress if regulators were to cut reimbursement rates in an attempt to enforce the cost reductions indicated by the standard frontier model. This underlines the importance of accounting for both observable and unobservable heterogeneity in the estimation of hospital cost frontiers.

However, this analysis is not without limitations. First, there is the risk of misspecification causing bias in the benchmark values used to characterize the posterior distribution governing Bayesian inference. Specifically, the cost of capital is missing from the equation; but in addition, the indicator for unit cost of labor is an aggregate over skill categories ranging from physicians to orderlies, and just counting the categories of internships offered likely constitutes a poor measure of educational 
services provided. Second, the distinction between observable and unobservable heterogeneity remains somewhat arbitrary; for instance, if measures of the vintage of hospital capital stock in terms of buildings and medical technology were available, a greater part of cost variability would be attributed to the observable component, likely causing the estimated influence of total heterogeneity on cost to be reduced. This point relates to a third weakness, which is that management inefficiency continues to be measured as a residual rather than by direct indicators. Therefore, by minimizing the contribution of this residual to cost variation, random parameter models might end up going too far in exonerating hospital management.

This said, the evidence presented here does suggest that the standard cost frontier model is insufficient for measuring hospital performance due its failure to take technological heterogeneity into account at all. While the evidence is limited to a sample of Swiss hospitals, the reasons for heterogeneity are of a general nature. They also apply to other heavily regulated or public sectors such as energy, education, and banking, underlining the importance of specifying cost frontier models that yield unbiased efficiency scores. 


\section{Appendix}

Table 5: Computation Codes for the Standard Frontier and the Random Parameter Model with Half Normal Distributed Efficiency Scores

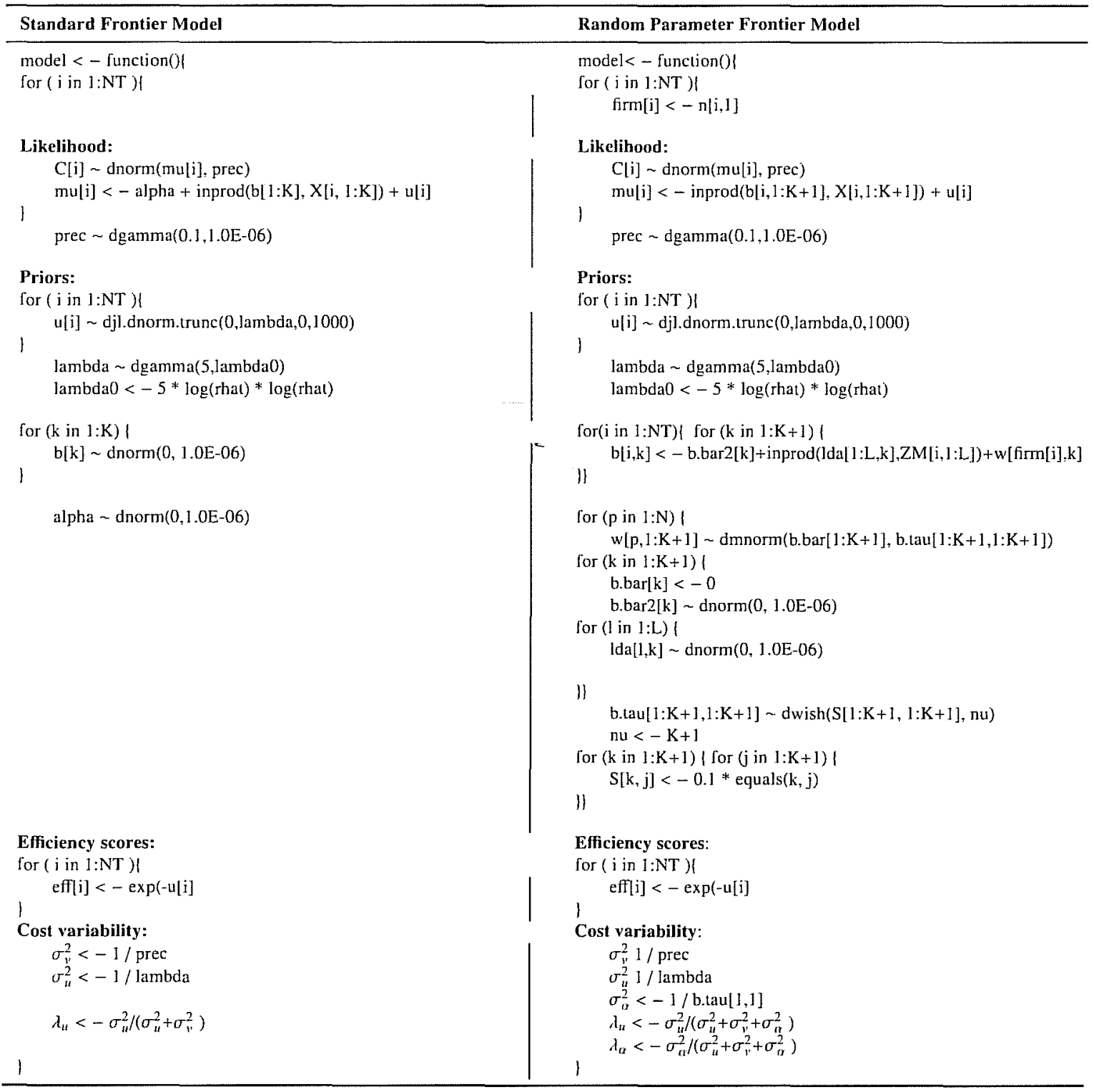


Table 6: Econometric Results of the Random Technology Parameters

\begin{tabular}{|c|c|c|c|c|c|c|c|c|c|c|}
\hline & RIFM & & & & RPFM & & & & & \\
\hline & CONSTANT & CONSTANT & P.CASE & OUTP.A & $P L$ & $B E D$ & $F M H$ & TREAT & $S U B$ & PORT.EI \\
\hline$\overline{\bar{\beta}}$ & $\begin{array}{c}3.106 \\
(0.32)\end{array}$ & $\begin{array}{r}4.948 \\
(1.11)\end{array}$ & $\begin{array}{c}0.485 \\
(0.115)\end{array}$ & $\begin{array}{c}0.013 \\
(0.011)\end{array}$ & $\begin{array}{c}0.384 \\
(0.110)\end{array}$ & $\begin{array}{c}-0.148 \\
(0.127)\end{array}$ & $\begin{array}{c}0.008 \\
(0.006)\end{array}$ & $\begin{array}{c}0.000 \\
(0.007)\end{array}$ & $\begin{array}{c}0.231 \\
(0.529)\end{array}$ & $\begin{array}{c}0.003 \\
(0.007)\end{array}$ \\
\hline $\mathrm{K} 111$ & $\begin{array}{c}0.693 \\
(0.14)\end{array}$ & $\begin{array}{r}0.439 \\
(3.04)\end{array}$ & $\begin{array}{c}0.170 \\
(0.780)\end{array}$ & $\begin{array}{c}-0.157 \\
(0.317)\end{array}$ & $\begin{array}{c}-0.013 \\
(0.745)\end{array}$ & $\begin{array}{c}-0.023 \\
(0.935)\end{array}$ & $\begin{array}{c}0.007 \\
(0.019)\end{array}$ & $\begin{array}{c}0.014 \\
(0.017)\end{array}$ & $\begin{array}{c}0.480 \\
(3.008)\end{array}$ & $\begin{array}{c}0.000 \\
(0.051)\end{array}$ \\
\hline $\mathrm{K} 112$ & $\begin{array}{r}0.273 \\
(0.07)\end{array}$ & $\begin{array}{r}0.865 \\
(2.56)\end{array}$ & $\begin{array}{c}-0.250 \\
(0.190)\end{array}$ & $\begin{array}{c}0.066 \\
(0.096)\end{array}$ & $\begin{array}{c}-0.166 \\
(0.300)\end{array}$ & $\begin{array}{c}0.282 \\
(0.41) 1\end{array}$ & $\begin{array}{c}-0.004 \\
(0.010)\end{array}$ & $\begin{array}{c}0.002 \\
(0.013)\end{array}$ & $\begin{array}{c}0.915 \\
(2.552)\end{array}$ & $\begin{array}{c}-0.008 \\
(0.014)\end{array}$ \\
\hline $\mathrm{K} 121$ & $\begin{array}{r}0.187 \\
(0.06)\end{array}$ & $\begin{array}{r}0.992 \\
(2.57)\end{array}$ & $\begin{array}{c}-0.231 \\
(0.251)\end{array}$ & $\begin{array}{c}0.028 \\
(0.096)\end{array}$ & $\begin{array}{c}-0.295 \\
(0.254)\end{array}$ & $\begin{array}{c}0.241 \\
(0.394)\end{array}$ & $\begin{array}{c}-0.007 \\
(0.006)\end{array}$ & $\begin{array}{c}0.010 \\
(0.011)\end{array}$ & $\begin{array}{c}1.024 \\
(2.574)\end{array}$ & $\begin{array}{c}0.007 \\
(0.013)\end{array}$ \\
\hline $\mathrm{K} 122$ & $\begin{array}{r}0.097 \\
(0.04)\end{array}$ & $\begin{array}{r}0.105 \\
(1.58)\end{array}$ & $\begin{array}{c}-0.220 \\
(0.157)\end{array}$ & $\begin{array}{c}-0.012 \\
(0.012)\end{array}$ & $\begin{array}{c}-0.183 \\
(0.145)\end{array}$ & $\begin{array}{c}0.474 \\
(0.205)\end{array}$ & $\begin{array}{c}-0.005 \\
(0.008)\end{array}$ & $\begin{array}{c}0.000 \\
(0.009)\end{array}$ & $\begin{array}{c}0.601 \\
(0.955)\end{array}$ & $\begin{array}{c}0.002 \\
(0.010)\end{array}$ \\
\hline $\mathrm{K} 231$ & $\begin{array}{r}0.082 \\
(0.07)\end{array}$ & $\begin{array}{c}0.676 \\
(2.16)\end{array}$ & $\begin{array}{c}-0.247 \\
(0.236)\end{array}$ & $\begin{array}{c}0.151 \\
(0.105)\end{array}$ & $\begin{array}{c}-0.129 \\
(0.276)\end{array}$ & $\begin{array}{c}0.046 \\
(0.229)\end{array}$ & $\begin{array}{c}-0.010 \\
(0.080)\end{array}$ & $\begin{array}{c}-0.005 \\
(0.019)\end{array}$ & $\begin{array}{c}0.682 \\
(0.987)\end{array}$ & $\begin{array}{c}0.002 \\
(0.014)\end{array}$ \\
\hline T.05 & $\begin{array}{r}0.034 \\
(0.01)\end{array}$ & $\begin{array}{r}0.462 \\
(0.33)\end{array}$ & $\begin{array}{c}0.078 \\
(0.047)\end{array}$ & $\begin{array}{c}-0.004 \\
(0.005)\end{array}$ & $\begin{array}{c}-0.148 \\
(0.077)\end{array}$ & $\begin{array}{c}-0.065 \\
(0.047)\end{array}$ & $\begin{array}{c}0.000 \\
(0.001)\end{array}$ & $\begin{array}{c}0.000 \\
(0.001)\end{array}$ & $\begin{array}{c}-0.054 \\
(0.044)\end{array}$ & $\begin{array}{c}0.000 \\
(0.001)\end{array}$ \\
\hline T.06 & $\begin{array}{r}0.129 \\
(0.01)\end{array}$ & $\begin{array}{r}1.148 \\
(0.43)\end{array}$ & $\begin{array}{c}-0.074 \\
(0.059)\end{array}$ & $\begin{array}{c}0.005 \\
(0.009)\end{array}$ & $\begin{array}{c}-0.152 \\
(0.105)\end{array}$ & $\begin{array}{c}0.069 \\
(0.063)\end{array}$ & $\begin{array}{c}0.000 \\
(0.001)\end{array}$ & $\begin{array}{c}-0.001 \\
(0.001)\end{array}$ & $\begin{array}{c}-0.071 \\
(0.062)\end{array}$ & $\begin{array}{c}0.000 \\
(0.001)\end{array}$ \\
\hline Т.07 & $\begin{array}{r}0.155 \\
(0.01)\end{array}$ & $\begin{array}{c}0.902 \\
(0.45)\end{array}$ & $\begin{array}{c}-0.130 \\
(0.062)\end{array}$ & $\begin{array}{c}0.004 \\
(0.010)\end{array}$ & $\begin{array}{c}-0.041 \\
(0.108)\end{array}$ & $\begin{array}{c}0.108 \\
(0.064)\end{array}$ & $\begin{array}{l}0.000 \\
(0.001)\end{array}$ & $\begin{array}{c}0.000 \\
(0.001)\end{array}$ & $\begin{array}{c}-0.057 \\
(0.064)\end{array}$ & $\begin{array}{c}0.000 \\
(0.001)\end{array}$ \\
\hline
\end{tabular}




\section{References}

Aigner, D., Lovell, C. A. K., Schmidt, P., 1977. Formulation and estimation of stochastic frontier production function models. Journal of Econometrics 6 (1), 21-37.

Battese, G., Coelli, T., 1992. Frontier production functions, technical efficiency and panel data: With application to paddy farmers in India. Journal of Productivity Analysis 3, 153-169.

Farrell, M., 1957. The measurement of productive efficiency. Journal of the Royal Statistical Scociety 120 (3), 253-281.

Farsi, M., Filippini, M., 2006. An analysis of efficiency and productivity in Swiss hospitals. Swiss Journal of Economics and Statistics (SJES) 142 (I), 1-37.

Farsi, M., Filippini, M., 2008. Effects of ownership, subsidization and teaching activities on hospital costs in Switzerland. Health Economics 17 (3), 335-350.

Farsi, M., Filippini, M., Greene, W., 2006. Application of panel data models in benchmarking analysis of the electricity distribution sector. Annals of Public and Cooperative Economics 77 (3), 271-290.

Greene, W., 2004a. Distinguishing between heterogeneity and inefficiency: stochastic frontier analysis of the world health organization's panel data on national health care systems. Health Economics 13 (10), 959-980.

Greene, W., 2004b. Interpreting estimated parameters and measuring individual heterogeneity in random coefficient models. Tech. rep.

Greene, W., 2005a. Fixed and random effects in stochastic frontier models. Journal of Productivity Analysis 23, 7-32.

Greene, W., 2005b. Reconsidering heterogeneity in panel data estimators of the stochastic frontier model. Journal of Econometrics 126 (2), 269-303.

Griffin, J., Steel, M., 2007. Bayesian stochastic frontier analysis using WinBUGS. Journal of Productivity Analysis 27, 163-176.

Hollingsworth, B., 2008. The measurement of efficiency and productivity of health care delivery. Health Economics 17 (10), 1107-1128.

Huang, H.-C., 2004. Estimation of technical inefficiencies with heterogeneous technologies. Journal of Productivity Analysis 21 (3), 277-296.

Jacobs, R., Smith, P. C., Street, A., 2006. Measuring Efficiency in Health Care. Cambridge University Press.

Keeler, E. B., 1990. What proportion of hospital cost differences is justifiable? Journal of Health Economics 9 (3), 359-365.

Koop, G., Osiewalski, J., Steel, M. F. J., 1997. Bayesian efficiency analysis through individual effects: Hospital cost frontiers. Journal of Econometrics 76 (1-2), 77-105.

Meeusen, W., van den Broeck, J., 1977. Efficiency estimation from Cobb-Douglas production functions with composed error. International Economic Review 18 (2), 435-44.

Newhouse, J. P., 1996. Reimbursing health plans and health providers: Efficiency in production versus selection. Journal of Economic Literature 34 (3), 1236-1263. 
Ntzoufras, I., 2009. Bayesian modeling using WinBUGS. Wiley Series in Computational Statistics. Wiley, Hoboken, NJ.

Orea, L., Kumbhakar, S. C., 2004. Efficiency measurement using a latent class stochastic frontier model. Empirical Economics 29 (1), 169-183.

Pitt, M. M., Lee, L.-F., 1981. The measurement and sources of technical inefficiency in the indonesian weaving industry. Journal of Development Economics 9 (1), $43-64$.

Schmidt, P., Sickles, R. C., 1984. Production frontiers and panel data. Journal of Business \& Economic Statistics 2 (4), 367-74.

Spiegelhalter, D. J., Best, N. G., Carlin, B. P., van der Linde, A., 2002. Bayesian measures of model complexity and fit. Journal of the Royal Statistical Society Series B 64, 583-640.

Steinmann, L., Dittrich, G., Karmann, A., Zweifel, P., 2004. Measuring and comparing the (in)efficiency of German and Swiss hospitals. The European Journal of Health Economics 5 (3), 216-226.

Steinmann, L., Zweifel, P., 2003. On the (in)efficiency of Swiss hospitals. Applied Economics 35 (3), 361-370.

Tsionas, E. G., 2002. Stochastic frontier models with random coefficients. Journal of Applied Econometrics 17 (2), 127-147.

Widmer, P. K., 2010. Does prospective payment increase hospital efficiency? evidence from a natural experiment. Working paper, Socioeconomic Institute.

Worthington, A., 2004. Frontier efficiency measurement in healthcare: A review of empirical techniques and selected applications. Medical Care Research and Review 61 (2), 1-36. 


\section{ECONOMICS DISCUSSION PAPERS \\ 2009}

DP

\section{NUMBER AUTHORS}

09.01

09.02

09.03

09.04

09.05

09.06

09.07

09.08

09.09

09.10

09.1]

09.12

09.13

09.14

09.15

09.16

09.17

09.18

09.19

09.20

09.21
Le, A.T.

$\mathrm{Wu}, \mathrm{Y}$.

Chen, M.H.

Velagic, R.

Mclure, M.

Chen, A. and Groenewold, N.

Groenewold, N. and Hagger, A

Clements, K. and Chen, D.

Clements, K. and Maesepp, M.

Jones, $\mathrm{C}$.

Siddique, M.A.B.

Weber, E.J.

Mclure, M.

Weber, E.J.

Tyers, R. and Huang, L.

Zweifel, P., Plaff, D. and

Kühn, J.

Clements, $\mathrm{K}$.

McLure, $\mathrm{M}$.

Harris, R.G. and Robertson, P.

Peng, J., Cui, J., Qin, F. and Groenewold, N.

Chen, A. and Groenewold, N.

\section{TITLE}

ENTRY INTO UNIVERSITY: ARE THE CHILDREN OF IMMIGRANTS DISADVANTAGED?

CHINA'S CAPITAL STOCK SERIES BY REGION AND SECTOR

UNDERSTANDING WORLD COMMODITY PRICES RETURNS, VOLATILITY AND DIVERSIFACATION

UWA DISCUSSION PAPERS IN ECONOMICS: THE FIRST 650

ROYALTIES FOR REGIONS: ACCOUNTABILITY AND SUSTAINABILITY

REDUCING REGIONAL DISPARITIES IN CHINA: AN EVALUATION OF ALTERNATIVE POLICIES

THE REGIONAL ECONOMIC-EFFECTS OF-IMMIGRATION: SIMULATION RESULTS FROM A SMALL CGE MODEL.

AFFLUENCE AND FOOD: SIMPLE WAY TO INFER INCOMES

A SELF-REFLECTIVE INVERSE DEMAND SYSTEM

MEASURING WESTERN AUSTRALIAN HOUSE PRICES: METHODS AND IMPLICATIONS

WESTERN AUSTRALIA-JAPAN MINING CO-OPERATION: AN HISTORICAL OVERVIEW

PRE-INDUSTRIAL BIMETALLISM: THE INDEX COIN HYPTHESIS

PARETO AND PIGOU ON OPHELIMITY, UTILITY AND WELFARE: IMPLICATIONS FOR PUBLIC FINANCE

WILFRED EDWARD GRAHAM SALTER: THE MERITS OF A CLASSICAL ECONOMIC EDUCATION

COMBATING CHINA'S EXPORT CONTRACTION: FISCAL EXPANSION OR ACCELERATED INDUSTRIAL REFORM

IS REGULATING THE SOLVENCY OF BANKS COUNTERPRODUCTIVE?

THE PHD CONFERENCE REACHES ADULTHOOD

THIRTY YEARS OF ECONOMICS: UWA AND THE WA BRANCH OF THE ECONOMIC SOCIETY FROM 1963 TO 1992

TRADE, WAGES AND SKILL ACCUMULATION IN THE EMERGING GIANTS

STOCK PRICES AND THE MACRO ECONOMY IN CHINA

REGIONAL EQUALITY AND NATIONAL DEVELOPMENT IN CHINA: IS THERE A TRADE-OFF? 


\section{ECONOMICS DISCUSSION PAPERS}

2010

DP

$\begin{array}{ll}\text { NUMBER } & \text { AUTHORS } \\ 10.01 & \text { Hendry, D.F. } \\ 10.02 & \text { Mclure, M., Turkington, D. and Weber, E.J } \\ 10.03 & \text { Butler, D.J., Burbank, V.K. and } \\ & \text { Chisholm, J.S. } \\ 10.04 & \text { Harris, R.G., Robertson, P.E. and Xu, J.Y. } \\ 10.05 & \text { Clements, K.W., Mongey, S. and Si, J. } \\ 10.06 & \text { Costello, G., Fraser, P., Groenewold, N. }\end{array}$

10.07

10.08

10.09

10.10

10.11

10.12

10.13

10.]4

10.15

10.16

10.17

10.18

10.19

10.20

10.21

10.22
Clements, K.

Robertson, P.E.

Fu, D., Wu, Y., Tang, Y.

Wu, Y.

Stephens, B.J.

Davies, M.

Tyers, R., Zhang, Y.

Clements, K.W., Lan, Y., Seah, S.P.

Robertson, P.E., Xu, J.Y.

Clernents, K.W., Izan, H.Y.

Gao, G.

Wu, Y.

Robertson, P.E.

Stevens, G.

Widmer, P.K., Zweifel, P., Farsi, M.

McLure, $\mathrm{M}$.

\section{TITLE}

RESEARCH AND THE ACADEMIC: A TALE OF TWO CULTURES

A CONVERSATION WITH ARNOLD ZELLNER

THE FRAMES BEHJND THE GAMES: PLAYER'S

PERCEPTIONS OF PRISONER'S DILEMMA, CHICKEN, DIC'TATOR, AND ULTIMATUM GAMES

THE INTERNATIONAL EFFECTS OF CHINA:S GROWTH, TRADE AND EDUCATION BOOMS

THE DYNAMICS OF NEW RESOURCE PROJECTS A PROGRESS REPORT

HOUSE PRICES, NON-FUNDAMENTAL COMPONENTS AND INTERSTATE SPILLOVERS: THE AUSTRAL]AN EXPERIENCE

REPORT OF THE 2009 PHD CONFERENCE IN ECONOMICS AND BUSINESS

INVESTMENT LED GROWTH IN INDIA: HINDU FACT OR MYTHOLOGY?

THE EFFECTS OF OWNERSHIP STRUCTURE AND INDUSTRY CHARACTERISTICS ON EXPORT PERFORMANCE

INNOVATION AND ECONOMIC GROWTH IN CHINA

THE DETERMINANTS OF LABOUR FORCE STATUS AMONG INDIGENOUS AUSTRALIANS

FINANCING THE BURRA BURRA MINES, SOUTH AUSTRALIA: LIQUIDITY PROBLEMS AND RESOLUTIONS

APPRECIATING THE RENMINBI

THE BIG MAC INDEX TWO DECADES ON AN EVALUATION OF BURGERNOMICS

IN CHINA'S WAKE: HAS ASIA GAINED FROM CHINA'S GROWTH?

THE PAY PARITY MATRIX: A TOOL FOR ANALYSING THE STRUCTURE OF PAY

WORLD FOOD DEMAND

INDIGENOUS INNOVATION IN CHINA: IMPLICATIONS FOR SUSTAINABLE GROWTH

DECIPHERING THE HINDU GROWTH EPIC

RESERVE BANK OF AUSTRALIA-THE ROLE OF FINANCE

ACCOUNTING FOR HETEROGENEITY IN THE MEASUREMENT OF HOSPITAL PERFORMANCE

ASSESSMENTS OF A. C. PIGOU'S FELLOWSHIP THESES 
THE ECONOMICS OF NONLINEAR PRICING: EVIDENCE FROM AIRFARES AND GROCERY PRICES

10.24 Halperin, D

FORECASTING METALS RETURNS: A BAYESIAN DECISION THEORETIC APPROACH

10.25 Clements, K.W., Si. J.

10.26 Chen, A., Groenewold, N., Hagger, A.J.

10.27

Siddique, A., Selvanathan, E.A., Selvanathan, S.
THE INVESTMENT PROJECT PIPELINE: COST ESCALATION, LEAD-TJME, SUCCESS, FAILURE AND SPEED

THE REGIONAL ECONOMIC EFFECTS OF A REDUCTION IN CARBON EMISSIONS

REMITTANCES AND ECONOMIC GROWTH: EMPIRICAL EVIDENCE FROM BANGLADESH, INDIA AND SRI LANKA 